\title{
Integration of 3D model THREETOX in JRODOS, implementation studies and modelling of Fukushima scenarios
}

\author{
V. Maderich ${ }^{1,2}$, I. Brovchenko ${ }^{1,2}$, A. Dvorzhak ${ }^{3}$, I. Ievdin ${ }^{2}$, V. Koshebutsky ${ }^{1,2}$ and R. Periáñez ${ }^{4}$ \\ ${ }^{1}$ Ukrainian Center of Environmental and Water Projects (UCEWP), Kiev, Ukraine. \\ 2 Institute of Mathematical Machines \& Systems Problems of National Academy of Sciences of Ukraine (IMMSP), Kiev, Ukraine. \\ 3 CIEMAT, Av. Complutense, 40, Madrid 28040, Spain. \\ ${ }^{4}$ University of Sevilla, Ctra. Utrera km. 1, 41013 Sevilla, Spain.
}

\begin{abstract}
The radionuclide transport model THREETOX was extended to include the multi-fractional sediments and two-step kinetics. The model was implemented into the decision support system JRODOS where forecasts of marine currents from the operational ocean models were used to predict dispersion of radionuclides. The results of simulation were compared with measurements for the Fukushima-Daiichi case study. The THREETOX model implemented into the JRODOS was applied to the stress test scenario for the ASCÓ nuclear power plant (Spain).
\end{abstract}

Keywords: marine radioactivity / transport model / decision support system / RODOS

\section{Introduction}

The Fukushima accident has demonstrated necessity of marine models integration into the decision support systems (DSSs). Within the frame of the European research project PREPARE the 3D circulation and radioactivity transport model THREETOX (Margvelashvili et al., 1997; Maderich et al., 2008) was improved and integrated into the Hydrological Dispersion Module of the JRODOS DSS (Raskob et al., 2011). The radioactivity transport model THREETOX was extended to include the multi-fractional sediments and two-step kinetics (Periáñez, 2003; Periáñez et al., 2015a). It can operate in two modes: full chain of hydrodynamics-sediment and radionuclide transport modules and only sediment and radionuclide transport modules. The THREETOX model implemented into the JRODOS was applied to the Fukushima Daiichi accident and to stress test scenario for the ASCÓ nuclear power plant (Spain).

\section{Integration of THREETOX model into JRODOS}

Using the THREETOX chain of hydrodynamics-sediment and radionuclide transport modules for operational forecasts of radioactivity dispersion in marine environment in result of accidents is cumbersome task due to several reasons: necessity of customization of full model for area of radioactivity contamination that cannot be done in advance e.g. in case of accident with ship powered by nuclear reactor; need in initialization of hydrodynamics model that for regional scales can take weeks and months; the simultaneous prediction of currents, temperature and salinity, sediment transport and radioactivity transport results in large computational burden when JRODOS is based on PC hardware.

The operational global and regional ocean forecast model were developed and implemented in operational practice past decade. These models are forced by operational meteorological models or even are components of coupled weather forecast modeling systems and provide 1-2 weeks forecasts of ocean currents and other parameters. These ocean forecast data can be used to predict short-term dispersion of radionuclides in the ocean and seas using transport module of THREETOX. This approach allows avoiding the above mentioned drawbacks in case of using of full version of THREETOX model.

The forecast procedure implemented into JRODOS includes several stages that are shown in flowchart in Figure 1:

- customization of transport model for given region;

- downloading of operational ocean forecast data;

- data interpolation on the transport model computational grid;

- calculation of vertical velocity and diffusivity from the horizontal components of velocity, free surface elevation, temperature and salinity provided by forecasts using continuity equation and $k-\varepsilon$ model of turbulence;

- prediction of suspended sediment transport concentration and erosion-deposition fluxes between bottom and water column;

- estimation of direct release source term;

- interpolation of atmospheric fallout predicted by JRODOS atmospheric dispersion models (ADM);

- the radioactivity distribution in the computational domain is predicted using radioactivity transport model with precalculated fields of currents and diffusivity and sources of activity. 


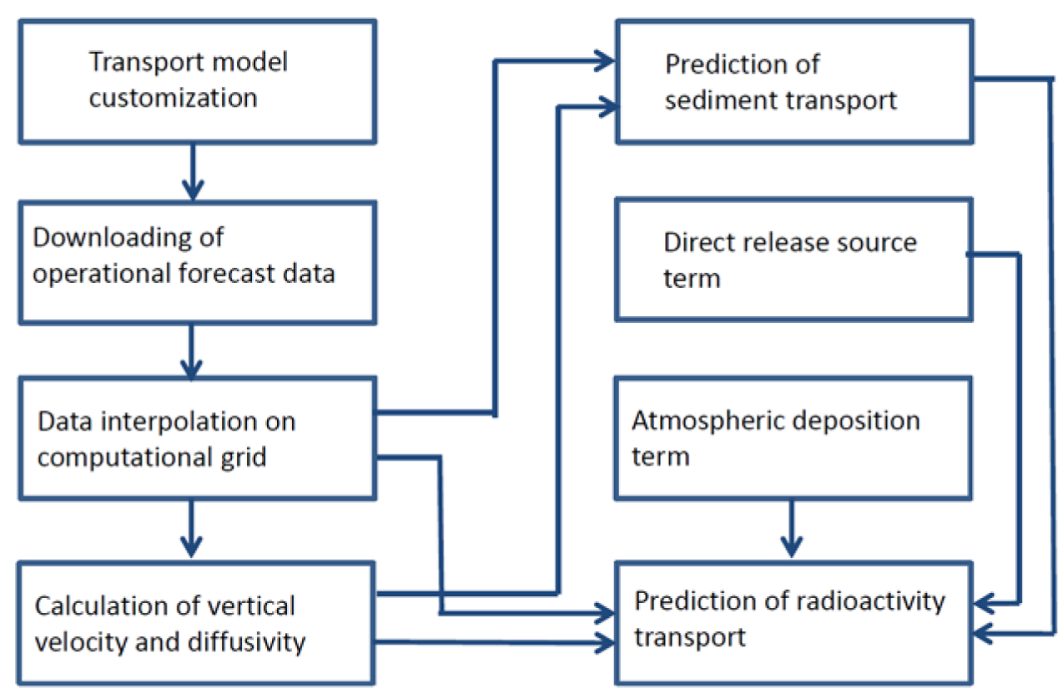

Figure 1. Flowchart of operational prediction of the radioactivity dispersion in the sea.

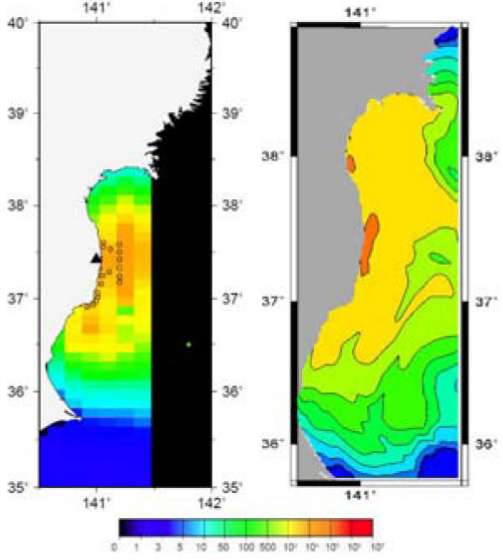

a)

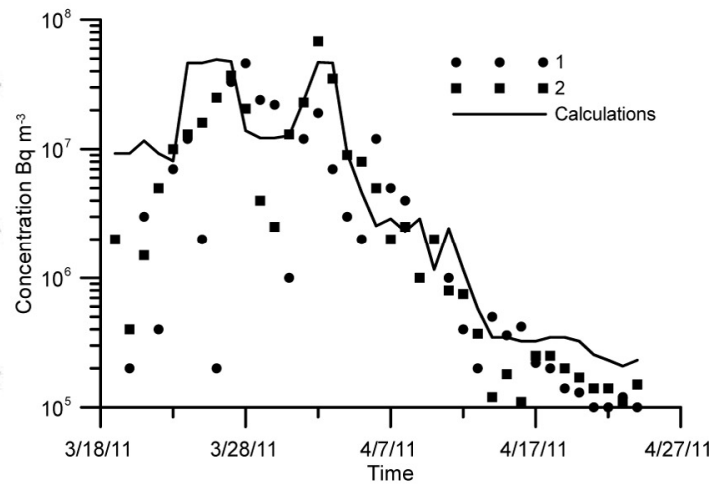

b)

Figure 2. (a) Distribution of ${ }^{137} \mathrm{Cs}$ at surface layer of water at May 1, 2011. Left panel are observations (Inomata et al., 2016). (b) Time series of observed (TEPCO, 2011) and simulated seawater-surface ${ }^{137} \mathrm{Cs}$ at stations T-1 and T-2.
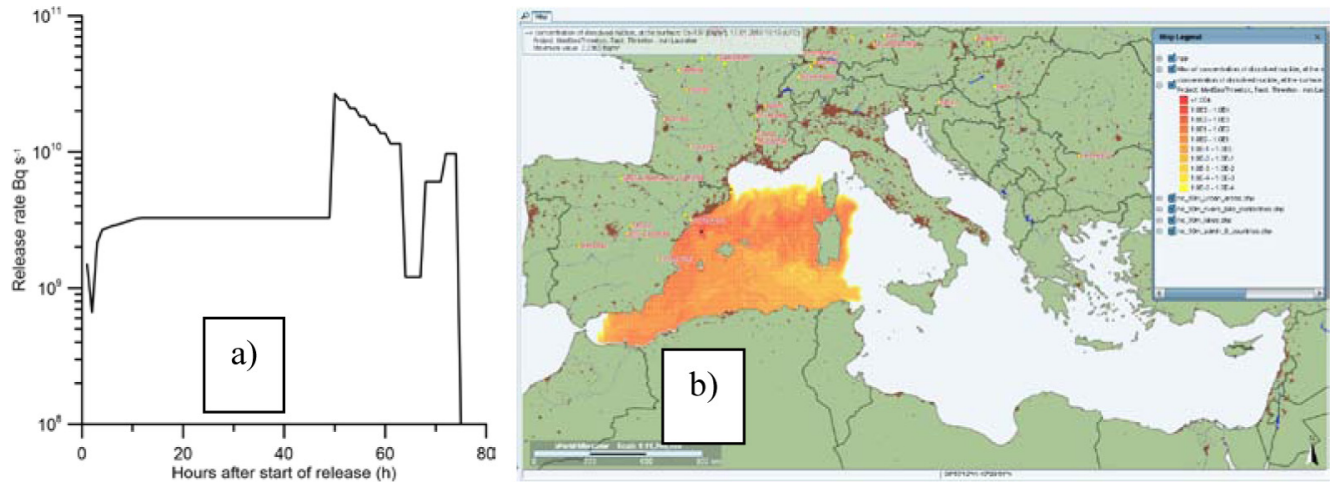

Figure 3. (a) The intensity of source of ${ }^{137} \mathrm{Cs}$ in the ASCÓ NPP stress test. (b) The simulated surface concentration of ${ }^{137} \mathrm{Cs}$ in water at 7 day after start of release. 


\section{Modeling results}

A catastrophic earthquake and tsunami that occurred on March 11, 2011 severely damaged the Fukushima Dai-ichi Nuclear Power Plant (FDNPP) and resulted in release of radionuclides in the atmosphere and ocean. The concentration of ${ }^{137} \mathrm{Cs}$ was simulated using THREETOX operational model from March to October 2011 for coastal area around the FDNPP (Figure 2) using the velocity fields from operational ocean model HYCOM (http://www.opc.ncep.noaa.gov/Cur rent_fcasts.shtml). The source term for direct release was used from Periáñez et al. (2015b).

A comparison of the predicted ${ }^{137} \mathrm{Cs}$ concentration in the water with measurements in the coastal areas around FDNPP is shown in left plate of Figure 2a. The spatial distribution of ${ }^{137} \mathrm{Cs}$ obtained from measurements using optimal interpolation (OI) analysis (Inomata et al., 2016) is shown in right plate of Figure 2a. The time series of observed and simulated seawatersurface ${ }^{137} \mathrm{Cs}$ at stations T-1 and T-2 (TEPCO, 2011) are shown in Figure $2 b$.

Another simulation was carried out following scenario of stress test for unit 1 of ASCÓ NPP (Spain) that is located in the province of Tarragona (Spain). According this scenario the intensity of source of accidental release ${ }^{137} \mathrm{Cs}$ was defined by (Gallego et al., 2016) as shown in Figure 3a. The results of an ADM simulation for total (dry and wet) deposition on the surface of Mediterranean Sea were used as input data. The transport of activity was calculated using the velocity fields from operational ocean model (Copernicus Marine Environment Monitoring Service, http://marine.copernicus.eu/web/ 69-interactive-catalogue.php). An example of surface distribution of surface concentration of ${ }^{137} \mathrm{Cs}$ at 7 day after start of release is shown in Figure $3 b$.

\section{Conclusions}

The radioactivity transport model THREETOX was extended to include the multi-fractional sediments and twostep kinetics and implemented into the DSS JRODOS. The forecasts of marine currents from the operational ocean models were used to predict transport of radioactivity. The results of simulation were compared with measurements for FukushimaDaiichi NPP case study. The THREETOX model implemented into the JRODOS was applied to the stress test scenario for the ASCÓ NPP (Spain).

Acknowledgement. The research leading to these results has received funding from the European Atomic Energy Community Seventh Framework Programme FP7/2012-2013 under grant agreement 323287.

\section{References}

Gallego E., Papush L., Monte L., Ievdin I. (2016) Integration of longterm radionuclide transport models MOIRA-LAKE and MOIRARIVER into Hydrological Dispersion Module of JRODOS, Radioprotection 51 (HS2) S141-S143.

Inomata Y., Aoyama M., Tsubono T., Tsumune D., Hirose, K. (2016) Spatial and temporal distributions of ${ }^{134} \mathrm{Cs}$ and ${ }^{137} \mathrm{Cs}$ derived from the TEPCO Fukushima Daiichi Nuclear Power Plant accident in the North Pacific Ocean by using optimal interpolation analysis, Environ. Sci. Process. Impacts 18, 126-136.

Maderich V., Heling R., Bezhenar R., Brovchenko I., Jeer H., Koshebutskyy A., Kuschan A., Terletska K. (2008) Development and application of 3D numerical model THREETOX to the prediction of cooling water transport and mixing in the inland and coastal waters, Hydrolog. Process. 22, 1000-1013.

Margvelashvili N., Maderich V., Zheleznyak M. (1997) THREETOX - a computer code to simulate three-dimensional dispersion of radionuclides in stratified water bodies, Radiat. Prot. Dosim. 73 (1-4), 177-180.

Periáñez R. (2003) Kinetic modelling of the dispersion of plutonium in the eastern Irish Sea: two approaches, J. Mar. Syst., 38, 259-275.

Periáñez R., Bezhenar R., Iosjpe M., Maderich V., Nies H., Osvath I., Outola I., de With G. (2015a) A comparison of marine radionuclide dispersion models for the Baltic Sea in the frame of IAEA MODARIA program, J. Environ. Radioact. 139, 66-77.

Periáñez R., Brovchenko I., Duffa C., Jung K.T., Kobayashi T., Lamego F., Maderich V., Min B.-I., Nies H., Osvath I., Psaltaki M., Suh K. (2015b) A new comparison of marine dispersion model performances for Fukushima releases in the frame of IAEA MODARIA program, J. Environ. Radioact. 150, 247-269.

Raskob W., Trybushnyi D., Ievdin I., Zheleznyk M. (2011) JRODOS: platform for improved long term countermeasures modelling and management, Radioprotection 46 (6), S731-S736.

TEPCO (Tokyo Electric Power Corporation) (2011) Influence to Surrounding Environment, Archives. Available at: www.tepco.co. $\mathrm{jp} / \mathrm{en} / \mathrm{nu} /$ fukushima-np/f1/index2-e.html.

Cite this article as: V. Maderich, I. Brovchenko, A. Dvorzhak, I. Ievdin, V. Koshebutsky, R. Periáñez. Integration of 3D model THREETOX in JRODOS, implementation studies and modelling of Fukushima scenarios. Radioprotection 51(HS2), S133-S135 (2016). 